\title{
MÉTODOS CONTRACEPTIVOS DE BARREIRA E DIU: TECNOLOGIA EDUCATIVA PARA DEFICIENTES VISUAIS
}

\author{
MECHANICAL CONTRACEPTIVE METHODS AND IUD: EDUCATIONAL \\ TECHNOLOGYFOR THE VISUALLY IMPAIRED \\ MÉTODOSANTICONCEPTIVOS DE BARRERAYDIU: TECNOLOGIAA \\ EDUCATIVAPARA INVIDENTES
}

\author{
Lorita Marlena Freitag Pagliuca ${ }^{+}$ \\ Jane Oliveira Rodrigues ${ }^{2}$
}

\begin{abstract}
RESUMO: O Planejamento Familiar oferece conhecimentos para decidir o número de filhos e o momento apropriado para tê-los. As informaçōes educativas em saúde têm se concentrado na comunicaçăo visual, dificultando seu acesso ao deficiente visual, portanto os objetivos deste estudo foram construir materiais educativos auto- instrucionais sobre métodos de barreira e DIU e permitir a avaliaçåo do material construido. Obedeceu-se dois momentos metodológicos: elaboração de métodos educativos explorando o tato e a audição seguido de teste por casal de cegos. Os dados da avaliação foram obtidos por entrevistas. Os resultados mostram que o conhecimento ocorreu com conteúdo e linguagem adequados, a comunicação privilegiada foi a verbal e a táctil e contribuiu para o resgate da cidadania do deficiente visual.
\end{abstract}

PALAVRAS CHAVE: Planejamento Familiar, saúde ocular, deficientes, cegueira.

\section{INTRODUÇÃO}

O Planejamento Familiar é uma prática cuja origem se encontra em épocas remotas. Nos registros históricos da reprodução humana, constatamos desde a antigüidade, uma preocupação pelo controle da natalidade. Esse fato motivou o surgimento de práticas anticoncepcionais, conforme registro nos papiros egipcios que datam de 1550 Antes de Cristo (Nogueira citado por Tenório, 1998).

O Planejamento Familiar é fundamental para a adequada estruturação da família. Oferece conhecimentos para decidir o número de filhos e o momento apropriado para tê-los. Quando uma pessoa aprende sobre planejamento familiar, passa a ter autonomia sobre seu corpo, aumentando sua capacidade de escolha.

O conhecimento do mundo exterior é efetuado essencialmente por meio do sentido da visão. $\mathrm{Na}$ ausência do mesmo, há prejuizo de acesso às informações disponiveis. A visão caracteriza-se como responsável por $80 \%$ das informações perceptiva das pessoas, permitindo, de imediato, que se avalie o significado de sua perda (Pagliuca,1993). Ainda segundo a mesma autora, a Organização Mundial de Saúde (OMS) estima que a cegueira afeta 500/100.000 habitantes no mundo, sendo que a visão dos outros milhões é tão precária que é necessário considerá-los cegos.

\footnotetext{
'Trabalho desenvolvido no Projeto Integrado Saúde Ocular/CNPq. Prêmio Zaíra Cintra Vidal, $1^{\circ}$ Lugar, $51 \mathrm{CBEn}$.

2 Prof". Dr." do Departamento de Enfermagem da Universidade Federal do Ceará (UFC).

${ }^{3}$ Enfermeira. Graduada pelo Curso de Enfermagem da UFC. Ex-bo/sista I.C./CNPq.
} 
O conceito de cegueira varia de acordo com os fins a que se destina, como: econômicos, legais, administrativos e educacionais. Segundo a OMS, a cegueira pode ser total ou parcial. A parcial, também conhecida como legal ou profissional, é aquela em que o individuo com acuidade visual corrigida nos dois olhos tem uma percepção igual ou inferior a 0,1 , ou campo visual tubular restrito a $20^{\circ}$ ou menos. Nestes casos, os indivíduos são apenas capazes de contar os dedos a uma curta distância e há os que só percebem vultos. Existem os que estão mais próximos da cegueira total, os que só têm percepção de projeção luminosa. Na cegueira total, o individuo não possui percepção luminosa (Cardoso; Pagliuca citado por Rocha, 1999).

Com freqüência as pessoas cegas vivem em condiçōes desvantajosas devido a barreiras fisicas e sociais. As sociedades precisam reconhecer que, apesar dos esforços feitos em prevenção, haverá sempre um determinado número de pessoas com deficiência e incapacidades e que devem ser identificados e eliminados os obstáculos à sua plena participação. Assim, quando pedagogicamente possivel, o ensino deve ser ministrado no sistema escolar normal, o trabalho deve ser proporcionado mediante emprego aberto e a moradia facilitada às suas necessidades (Corde,1997).

Usualmente, as informações educativas têm se concentrado na comunicação visual, o que dificulta seu acesso às pessoas cegas. Estamos numa época em que predominam as imagens. No que pertine às informações básicas de saúde, há pouco material informativo adaptado a realidade destes individuos.

O interesse pela temática da educação em saúde para pessoas com necessidades especiais tem nos acompanhado já há algum tempo. Em trabalho anterior abordamos o ensino de contraceptivos comportamentais para deficientes visuais, com o emprego da comunicação táctil, em curso ministrado por enfermeira. (Rodrigues; Pagliuca, 1998). Apesar dos resultados obtidos parece que este caminho não permitirá disponibilizar estas informações para todos os deficientes visuais. Portanto, outras abordagens devem ser experimentadas, sempre confiando na capacidade de participação e auto-cuidado do deficiente visual.

Como resposta às reflexões aqui mencionadas, estudam-se alternativas para educação em saúde sobre planejamento familiar através dos métodos de barreira e DIU (Dispositivo Intra Uterino), destinado a pessoas cegas ou deficientes visuais. Para esclarecer o tema e a abordagem adotada, consultamos a literatura sobre educação especial, a educação para a liberdade de Paulo Freire e o planejamento familiar.

\section{O CEGO EA EDUCAÇÄO PARAA LIBERDADE DE PAULO FREIRE}

A educação é um direito de todos e permite aos individuos uma participação consciente da realidade social. Na área da educação do deficiente visual são atribuiçōes do governo promover a criação e o desenvolvimento de recursos para a educação e reabilitação a fim de que o deficiente visual possa transpor os limites da deficiência e inserir-se no contexto social.

Os educadores especializados afirmam que as necessidades educacionais específicas dos cegos são a aprendizagem do Braille. o amplo uso de experiências auditivas, táteis e cinestésicas e o treinamento especial da mobilidade. Referindo-se aos alunos com visão subnormal, esses mesmos autores destacam que tais alunos necessitam de ampliação e de material impresso em formatos especiais (Mazzotta, 1982). A comunicação também pode ser instituida através da escrita e datilografia Braille.

Paulo Freire (1994), criou o conceito da educação como prática libertadora, seu método estimula a colaboração, a decisão, a participação e a responsabilidade social e política. Sua filosofia postula que o educando se veja vivendo e produzindo em determinada sociedade $e$ lutando por uma sociedade mais justa, mais democrática, na qual todos possam ter vez e voz. O pensamento do autor se aplica de maneira perfeita à educação dos adultos e, cremos nós, no aprendizado dos métodos de planejamento familiar. 
A Constituição Federal Brasileira (BRASIL, 1988, p.148) postula que, fundamentado nos principios da dignidade da pessoa humana e da paternidade responsável, o planejamento familiar é livre decisão do casal, competindo ao Estado propiciar recursos educacionais e científicos para o exercicio desse direito, vedada qualquer forma coercitiva por parte de instituições oficiais ou privadas.

Os serviços de planejamento familiar são os responsáveis pela implementação deste artigo e, consultados os casais quanto ao número de filhos que desejam ter, orientam sobre os métodos anticoncepcionais e sobre o funcionamento dos órgãos sexuais e reprodutivos (FUNDAÇÃO VICTOR CIVITA, 1998).

A opção do uso de um determinado método contraceptivo parte da informação disponibilizada para o usuário, sendo esclarecido o que é, como se utiliza e suas vantagens e desvantagens. Portanto deve-se oferecer informações sobre todos os métodos anticoncepcionais para aumentar a liberdade de escolha.

A escolha dos métodos contraceptivos é determinada pela etapa de vida das pessoas, a indole de suas relações sexuais, o risco de contrair doença sexualmente transmissivel, sua condição de saúde, o acesso aos serviços, a disponibilidade do método e o tipo de orientação que recebe. A forma que o sistema de prestação de serviços aborda todas estas questões influencia na qualidade geral dos mesmos (Finger,1998),

A educação em saúde para o planejamento familiar está disponibilizada nos postos e centros de saúde do serviço público no Brasil e ocorre de maneira até razoável para os videntes. Quando se refere aos deficientes visuais a situação é outra, pois dispõem de cartilhas e fitas de video em VHS onde predominam as imagens. A inexistência de recursos de ensino para os deficientes visuais caracteriza violação dos direitos humanos pois impede seu acesso a informação.

Portanto, levando-se em conta as necessidades especiais dos deficientes visuais e a importância da educação em saúde para um planejamento familiar consciente entre casais, são objetivos deste estudo: Construir materiais educativos auto-instrucionais sobre métodos de Planejamento Familiar de barreira e DIU para deficientes visuais e cegos e, compartilhar com o usuário a avaliação do material construido.

\section{METODOLOGIA}

Estudo tecnológico, tipo exploratório e descritivo, com abordagem qualitativa, sobre material e método educativo para educação em saúde para cegos. O estudo tecnológico permite a criação e teste de materiais e métodos, já a pesquisa qualitativa responde a questões muito particulares, preocupa-se com um nivel de realidade que não pode ser quantificado. Ou, seja, ela trabalha com o universo de significados, motivos, aspiraçöes, crenças, valores e atitudes, o que corresponde a um espaço mais profundo das relações, dos processos e dos fenômenos que não podem ser reduzidos a operacionalização de variáveis (Deslandes ,1994).

No primeiro momento foram criados os materiais educativos no laboratório de enfermagem, contou-se com auxilio de estúdio de som para a gravação da fita K7. A etapa seguinte compreendeu a organização do método de ensino concatenando o uso do material auditivo com o de toque. Concluidas estas etapas passou-se à fase experimental com o auxilio de um casal de cegos para realizar o teste.

O casal, após um primeiro encontro para esclarecimento dos objetivos da pesquisa, concordou em receber a pesquisadora em sua residência. Garantiu-se sigilo e liberdade para abandonar o estudo a qualquer momento. Ambos eram portadores de cegueira absoluta, adultos, alfabetizados em Braille e que expressaram no primeiro contato desejo de planejar sua família. 
O kit estava acompanhado de orientações em Braille que também foram explicados oralmente e foi combinado para o dia seguinte a sua devolução e entrevista para avaliação do material. $\mathrm{Na}$ entrega do kit certificamo-nos de que as pessoas dispunham de rádio gravador para reprodução da fita $k 7$.

Posteriormente, na entrevista para avaliar o material educativo, foram utilizadas questões norteadoras, que estimularam a crítica do analista, dentre elas: comente suas impressões sobre este material: este Kit conseguiu Ihe transmitir informaçōes sobre planejamento familiar? a linguagem está acessivel aos deficientes visuais?, como você se sentiu ao ouvir esta fita?, c ao tatear o material?, quais suas sugestões para melhorar este material ?. As entrevistas foram individuais e, com a concordância dos entrevistados, gravadas.

Os resultados do estudo estão apresentados em dois momentos distintos, no primeiro descreve-se os materiais educativos sobre métodos de barreira e DIU criados para deficientes visuais e cegos; no segundo, a análise da avaliação realizada pelo casal de cegos. As fitas gravadas nas entrevistas foram ouvidas exaustivamente, transcritas, e buscou-se organizar os dados de acordo com as questões norteadoras. A análise da avaliação realizada pelo casal de cegos foi organizada em temáticas subdivididas em categorias. (Rodrigues, Leopardi,1999).

\section{APRESENTAÇÃO EANÁLISE DOS DADOS}

O material educativo oferecido para uso e avaliação dos cegos compunha-se de um manual de instruções, uma fita K7 e materiais para serem explorados pelo tato. Estava contido em uma pasta com $2 \mathrm{~cm}$ de altura; $10 \mathrm{~cm}$ de largura e $13,4 \mathrm{~cm}$ de comprimento e identificadas com escrita Braille.

O manual de instruções em Braille esclarecia que o material seria de uso individual, auto-instrucional, podendo ser ouvido tantas vezes quantas julgasse necessário, com as interrupçōes que desejasse. Foi sugerido manter o material organizado para facilitar consultas subsequentes.

Inicialmente foi preparado um texto, baseado na revisão de literatura, sobre a temática a ser abordada. Sobre o texto informativo foi criada uma estória comum no cotidiano, um casal de namorados que se depara com uma gravidez não planejada. Sobre este cenário foi gravada uma fita K-7 em estúdio, com linguagem radiofônica, contando com a participação de um casal de locutores profissionais, outro de atores amadores. Enquanto os atores interpretavam a estória de um namoro e posterior gravidez não desejada, os locutores informavam sobre a anatomia e filosofia dos sistemas reprodutores, os métodos de planejamento familiar de barreira e DIU. 0 fundo musical instrumental, visando aumentar a capacidade de concentração do ouvinte, foi introduzido sempre que havia indicação de exploração táctil de algum material.

Os materiais tácteis foram organizados em pastas e caixas, identificadas por números e com seus conteúdos descritos. As estruturas anatômicas do sistema reprodutor masculino e feminino foram reproduzidas em folhas de cartolina, com contomos em alto relevo, obtido com o punção, objeto pontiagudo para escrita Braille. As estruturas estavam identificadas com seus respectivos nomes, alguns simplificados para a linguagem popular. Os desenhos das estruturas anatômicas foram realizados das externas para as internas, com a inclusão progressiva de novos elementos, permitindo sua exploração pelo tato. Vale ressaltar que para o sistema feminino foram usados apenas três pranchas, enquanto para o masculino, o dobro.

A pasta de número um continha as pranchas reproduzindo ovários, trompas de Falópio, útero e vagina. A pasta número dois continha a reprodução do pênis com canal aferente e deferente, testiculo e escroto.

As cinco caixas restantes continham, respectivamente, o espermicida vaginal com aplicador; diafragma; camisinha masculina e uma prótese com a forma de pênis; camisinha feminina e DIU. O texto da gravação orientava a exploração táctil do material ao mesmo tempo 
que instruia sobre seu uso. A prótese do pênis servia para o treino de "vestir" a camisinha.

O segundo objetivo, avaliação do material e método educativo, previu a participação do casal de cegos. Este explorou o material, na perspectiva da análise de sua qualidade e pertinência de uso em larga escala para esta clientela, bem como sugerir aperfeiçoamentos. A análise cuidadosa de suas entrevistas permitiu identificar as temáticas: conhecimento e comunicação. A primeira temática está subdividida em: conteúdo e linguagem e a segunda, em verbal e táctil. Passa-se a descrevê-las.

\section{TEMÁTICA: Conhecimento}

O conhecimento possui dois elementos: o sujeito e o objeto. O sujeito é aquele que capta e o objeto é aquele que é captado. O conhecimento é $\mathrm{O}$ ato ou efeito de conhecer. Conhecer significa associar semelhança com aquilo que é conhecido. Conhecer eqüivale a receber e a transmitir mensagens do meio a que se pertence e ter uma mensagem a transmitir através de uma linguagem ( $S a ́, 1973$ ).

O conhecimento traz em si um conteúdo e uma linguagem. O mesmo conteúdo pode ser abordado sob diferentes formas, aqui o conteúdo selecionado refere-se aos métodos de planejamento familiar por barreira e DIU e, conforme as falas que se seguem pode-se perceber que o conteúdo foi compreendido pois os entrevistados os repetem.

...vai falando em espermicidas, camisinha e ai a gente vai entendendo melhor sobre planejamento familiar.

Deixa a pessoa a par de como acontece a fecundação e como evitar filhos.

Ajuda a pessoa a conhecer o corpo do homem e da mulher dos nomes e detalhes sobre eles.

O conteúdo é o que se contem em alguma coisa. Conteúdo de revistas, livros, imagens cinematográficas, palavras, textos entre outros. O conteúdo possui caracteristica e significação. O conteúdo pode ser manifesto ou semântico ou conteúdo com harmonização de sentimentos ou latente (Rodrigues; Leopardi, 1999).

Conforme foi relatado anteriormente, foi abordado a visão social do planejamento familiar, a anatomia e fisiologia do homem e da mulher, a concepção e os métodos de barreira e DIU e estes conteúdos estão sendo reproduzidos nas falas do casal cego.

O segundo aspecto do conhecimento refere-se a linguagem, conceituada como um conjunto de sinais que serve para o fim de comunicação. Cada tipo de linguagem (mímica, de trânsito, jurídica) manifesta-se através de uma língua (ou código). A linguagem radiofônica compreende um emissor (locutor); receptor (ouvinte); código comum (língua); canal físico (aparelho fonador, rádio, e ouvido); contexto (o ambiente lingüístico e o social); e a mensagem (o discurso). A mensagem está sujeita a seleção e a combinação de signos pelos individuos falantes ( Sá,1973).

A linguagem pode ser, ainda, popular ou científica. Para o conteúdo da fita buscou-se uma linguagem clara e atraente, mais próxima dos termos populares e adaptada à linguagem radiofônica, pois sabemos que a comunicação depende de uma linguagem comum, que permite a compreensão da mensagem na educação em planejamento familiar.

Não usou palavras dificeis.

O material estava bem explicado.

É uma redação simples e bem direta.

Com termos do dia a dia que todo mundo usa.

Nestas falas observamos que a linguagem radiofônica utilizada na fita k-7 foi efetiva na transmissão do conhecimento, demonstrando a importância de vocabulários do dia a dia para 
facilitar o aprendizado.

\section{TEMÁTICA: Comunicação}

As teorias de comunicação são unânimes em indicar como elementos do processo de comunicação o emissor ou remetente, o receptor ou destinatário e a mensagem. Classificam a comunicação em verbal e não verbal. Classificam, ainda, em comunicação escrita, falada, por gestos, em grupo, táctil, sonora, por símbolos, entre outras (Pagliuca,1996).

O material educativo criado, destinado ao deficiente visual, privilegiou a comunicação verbal e táctil através, respectivamente, da linguagem radiofônica e da exploração táctil. A utilização de locutores com voz feminina e masculina também contribuiu para reproduzir ambiente de casal, com responsabilidades partilhadas. Foi utilizado fundo musical com instrumental em piano visando aumentar a capacidade de concentração dos ouvintes.

Com a fita ajudou porque ele (o locutor) vai falando...

Eu coloquei os headphones e eu fiquei compenetrada, quietinha para entender direitinho tudo[...]

A comunicação verbal é aquela associada a palavra escrita ou falada. A comunicação pode não ser efetiva quando a maneira de falar distrai a atenção do que foi dito ou quando o próprio emissor encontra dificuldades de falar (Silva, 1996).

Pelos depoimentos percebemos que a atenção no decorrer da gravação foi mantida e que os recursos utilizados para tal fim foram relativamente eficazes, apesar dos entrevistados comentarem que os atores amadores não fizeram uma boa entonação na interpretação e sugeriram a participação de atores profissionais.

A comunicação táctil refere-se a transmissão de mensagens através do tato e por meio do toque. Envolve pressão e local onde se toca (Silva, 1996). Segundo Pagliuca (1996), na criação de materiais sobre educação em saúde, com a utilização do tato, deve-se atentar quanto a importância de conceitos sobre ponto, linha, plano e textura visando a facilitar o aprendizado e a compreensão do material educativo através da exploração táctil. Compreender que o ponto é uma diminuta marca no espaço e que em conjunto torna-se linha. O plano é o espaço onde se concebe a criação e este plano pode ser positivo (relevo) e negativo, ou seja, 0 plano positivo é aquele real e o plano negativo é o plano em que não há relevo e denomina-se pausa e repouso. A textura deriva da qualidade física do plano e tem relação direta com o material empregado, podendo ser percebido pelo olhar e pelo tato.

No kit auto-instrucional foram utilizados estruturas planas com contorno em alto relevo que permitiram a compreensão relativa entre as estruturas do sistemas reprodutores masculino e feminino. $O$ uso associado de papéis de diferentes texturas permitem diferenciar as estruturas anatômicas nos diversos planos.

Foram registradas dificuldades e criticas ao explorarem o sistema reprodutor masculino devido ao tamanho reduzido das estruturas anatômicas e que não evidenciaram riquezas de detalhes. Como sugestão mencionaram um contomo mais acentuado em alto relevo e dar mais espaços entre uma estrutura e outra. Estas sugestões foram incorporadas ao material definitivo.

So precisa melhorar as folhas quanto ao alto relevo.

Acho que se fosse um pouco mais em alto relevo dava para ver melhor

O espaço maior entre uma coisa e outra( entre um órgão e outro).

Pode ser feito também com cordão que não seja muito grosso e entăo colar.

O da mulher estava mais bem distribuida (ao se referir a posiçăo relativa de cada uma das estruturas). 


\section{Só consegui identificar o testículo e o saco escrotal}

No caso do contato com a camisinha feminina associada a explanação oral sobre a mesma, os deficientes visuais relataram que ai tornaram esta experiência concreta pois não haviam vivenciado tal momento antes, apenas tinham ouvido falar deste método. Nas próximas falas observa-se a capacidade de concentração que a fita proporcionou e, a sincronia entre a comunicação verbal e táctil.

Eu já tinha ouvido falar em camisinha feminina mas foi a primeira vez que tive contato com uma.

Ele (o locutor) começou a explicar foi ficando melhor dando os espaços de tempo.(Para exploração táctil).

A análise da qualidade e aplicabilidade do material educativo se encerra aqui. Passamos então à reflexão na perspectiva da educação como prática da liberdade, conforme proposta por Paulo Freire (1994), buscando compreender se o processo permitiu trilhar o caminho da construção da cidadania. Vejamos como isto se deu.

Cidadania é a qualidade de cidadão, é o individuo no gozo de seus direitos de cidadão, tanto os chamados direitos humanos - à vida, à saúde, à educação, à moradia- quanto aos direitos civis - liberdade, igualdade jurídica e justiça ( Buffa, 1993).

O fato do kit ser auto-instrucional foi valorizado pelos entrevistados, ficando evidente que seu controle sobre o modo de aprender reforça sua independência.

Deixa a pessoa a vontade, livre.

Porque a pessoa vai ouvir( a fita) no horário que tiver vontade de estudar.

É bem democrático.

Deixa você sozinho. Não tem aquela pessoa do lado que deixa você inibido.

Materiais educativos disponibilizados em larga escala, segundo Atkinson (1989), tem a vantagem potencial de atingir um grande número de pessoas através do uso repetido. $O$ aprendiz pode selecionar o momento de assistir, afim de combinar com seus horários pessoais. $O$ aprendiz pode também ouvir repetidamente para melhorar a compreensão do conteúdo.

Questões sociais amplas, como o direito à educação especial e sua negação, com altos indices de analfabetismo entre os cegos, também foram verbalizados pelos cegos que colaboraram com o estudo, patenteando suas preocupações consigo próprio e com outros e sua capacidade de reflexão social.

[...] mesmo considerando que infelizmente o grau de estudo dos deficientes visuais é baixo por conta das dificuldades de material didático e econômica, da falta de vontade das autoridades na área educacional como por exemplo a impressora Braille, com o ensino itinerante [...]

No que se refere ao Ensino Itinerante, deve-se destacar que é considerado um auxilio especial, por proporcionar atendimento a alunos que se encontram matriculados na escola regular. Os professores especializados visitam as escolas, onde prestam assistência aos professores comuns e aos alunos deficientes visuais. Basicamente, o objetivo deste recurso é que recebam os benefícios do programa educacional proporcionado a todas as crianças e adultos da escola (Mazzotta,1982).

[...]me senti bem de estar aprendendo mais e por estar participando de um trabalho sério que irá ajudar os deficientes visuais a obter conhecimentos, como por em 
prática o seu planejamento familiar

Este último depoimento fica registrado como reconhecimento do compromisso de cidadão, assumido pelo casal de cegos que se dispôs a colaborar neste estudo, na luta por transformação para uma sociedade mais justa em que a educação em planejamento familiar seja de qualidade e para todos.

\title{
REFLEXÕES FINAIS
}

Estamos numa sociedade extremamente discriminatória em relação às pessoas com necessidades especiais, o que compromete o acesso a educação em saúde, determinada pela falta de oportunidades iguais de aprendizagem. Percebemos que houve receptividade por parte dos deficientes visuais em relação ao kit auto-instrucional criado. Eles elogiaram e criticaram os materiais contribuindo para o seu aperfeiçoamento.

O tema planejamento familiar é de interesse das pessoas cegas e o material educativo parece ter respondido as suas necessidades de aprendizagem. Os depoimentos mostram que o conhecimento foi transmitido adequadamente no seu conteúdo e linguagem, a comunicação verbal e táctil pode ser melhorada usando apenas locutores profissionais e, o sistema reprodutivo masculino ser subdividido em maior número de pranchas.

A pedagogia proposta por Paulo Freire (1994) responde às nossas crenças e valores quanto a educação e cidadania, pois é fundamentada numa filosofia cuja meta é o engajamento do individuo na luta por transformações sociais. Confirma a urgência de uma educação capaz de despertar a consciência critica dos deficientes visuais para que possam inserir-se nesta luta, onde haja a democratização do conhecimento necessário para o exercicio pleno da cidadania.

\begin{abstract}
Family planning is fundamental for the appropriate structuring of the family. This offers knowledge to decide on the number of children, and the most adequate moment to have them. The current health information being advertised is based on visual communication. This fact hinders the access of visually impaired people to such important knowledge. The present study has as objectives the creation of self-instructional educational material concerning mechanical contraceptive methods and IUD, as well as its evaluation. The research was divided in two methodological parts. In the first part, methods that explored the senses of hearing and touch were elaborated. In the second part, these methods were tested by a sight impaired couple. The data for the evaluation was obtained through interviews. Results show that the use of appropriate content and language facilitate the understanding of the contraceptive methods by these people. Verbal and tactile communication was favored and contributed on the reconstruction of citizenship for the visually impaired.
\end{abstract}

KEYWORDS: family planning, visually impaired, blindness, eye health

RESUMEN: La Planificación Familiar ofrece conocimientos para decidir el número de hijos y el momento apropriado para tenerlos. Las informaciones disponibles en educación para la salud se han concentrado en una comunicación visual, lo que impide su acceso a las personas ciegas. El presente estudio tiene como objetivos: construir materiales educativos autoinstruccionales sobre los métodos de barrera y DIU y permitir la evaluación del material construido. Se han seguido dos momentos 
metodológicos: elaboración de métodos educativos que utilizan el tacto y la audición y por último un test presentado por una pareja de invidentes, dos datos de la evaluación se obtuvieron com entrevistas. Los resultados demuestram que hubo un aprendizaje de contenidos, com un lenguaje adecuado; que la comunicación mejor fue la verbal y táctil y, sobre todo, que ha contribuido para el rescate de los invidentes como ciudadanos.

PALABRAS CLAVE: planificación familiar, salud de los invidentes.

\section{REFERÊNCIAS BIBLIOGRÁFICAS}

ATKINSON, L. D. Fundamentos de Enfermagem: introduçăo ao processo de Enfermagem. Editora Guanabara Koogan S.A. 1989.

BRASIL. Constituição Federal. Brasilia: Centro Gráfico, 1988.

BRASIL. Ministério da Saúde. Assistência ao Planejamento Familiar: normas e manuais técnicos. Brasilia, 1992.

BUFFA, Ester. Educação e cidadania. Ester Buffa, Miguel G. Arroyo, Paolo Nosella- 4. ed. Săo Paulo: Cortez, 1993.

CARDOSO, M.V.L.M.L.; PAGLIUCA, L.M.F. O Caminho da Luz. Fortaleza: Pós- Graduaçăo DENFNFC., 1999. 95p.

CORDE. Coordenadoria Nacional para Integraçăo da Pessoa Portadores de Deficiência. Normas e recomendações internacionais sobre deficiências. Brasilia, 1997

FINGER, W. R. Melhorias nos serviços de planejamento familiar e a perspectiva do cliente. Rev. Network en español, Family Health International, v.19, n. 1, out. 1998.

FREIRE, P. Educaçäo como prática de liberdade. Rio de Janeiro: Paz e Terra, 1994. 158p.

FUNDAÇÃo VICTOR CIVITA. Como planejar a familia. Săo Paulo: Abril, 1987.

MAZZOTTA, M. J. S. Fundamentos de educação Especial. Săo Paulo: Livraria Pioneira, 1982. 55p.

MINAYO, M.C.S. Pesquisa social: teoria, método e criatividade. Petrópolis: Vozes, 1994. 80 p.

NOGUEIRA, R. A. O planejamento familiar entre casais de surdos: relato de uma metodologia educativa Fortaleza, 1998.81p. Dissertação (Mestrado). Centro de Ciências da Saúde, Universidade Federal do Ceará.

PAGLIUCA, L.M.F. A arte da comunicação na ponta dos dedos - a pessoa cega. Rev. Latino- Am. Enfermagem, Ribeirăo Preto, v. 4, abr. 1996. Número especial.

Assistência de Enfermagem ao deficiente visual: aplicação da teoria das necessidades humanas básicas a pacientes com indicaçăo de transplante de córnea. Fortaleza: Universitária, 1993. 
ROCHA, H. Ensaı sobre a problemática da cegueira prevenção-recuperação-reabilitação. Belo Horizonte: Fundação Hilton Rocha, 1987. 354 p

RODRIGUES, M.S.P. LEOPOLDI, M.T. O método de análise de conteúdo uma versão para enfermeiros Fortaleza: Fundação Cearense de Pesquisa e Cultura, 1999, 118p.

RODRIGUES, M.L. PAGLIUCA, L.M.F. Mètodos contraceptivos comportamentais: tecnologia educativa para deficientes visuais. Revista Gaúcha de Enfermagem, Porto Alegre, v. 19, n. 2, p. 147-153, 1998.

SA,A. Fundamentos Cientificos da Comunicação. Petrópolis: Vozes, 1973.

SILVA, M.J.P Comunicaçāo tem remédio: a comunicação nas relações interpessoais em saúde São Paulo: Editora Gente, 1996. 